\title{
MELIPONA (MICHMELIA) CAPIXABA, UMA NOVA ESPÉCIE DE MELIPONINAE (HYMENOPTERA, APIDAE) DO SUDESTE DO BRASIL ${ }^{1}$
}

\author{
Jesus S. Moure ${ }^{2}$ \\ João M.F. Camargo ${ }^{3}$
}

\begin{abstract}
MELIPONA (MICHMELLA) CAPIXABA, A NEW SPECIES OF MELIPONINAE (HYMENoptera. ApIDAE) From SOUTHEarsten Brasil. This species from the Mata Atlântica resembles Melipona lateralis Erichson, 1848 and M. seminigra Friese, 1903 from the Amazonian Region. It can be easily distinguished from the first and its nearest relative, $M$. scutellaris Latreille, 1811 by having a more shining mesoscutum and from the second by the yellow facial markings.
\end{abstract}

KEY WORDS. Taxonomy, Melipona, Neotropics

Melipona capixaba foi descoberta no Sudeste do Brasil, em Domingos Martins (Espírito Santo), pelo prof. Gabriel A. Rodrigues de Melo, da Universidade Federal de Uberlândia (Minas Gerais), quando ainda integrava o grupo do Prof. Lúcio de Oliveira Campos, da Universidade Federal de Viçosa, Minas Gerais.

Atualmente, esta espécie, está sendo objeto de um programa de preservação desenvolvido pelo Prof. Warwick E. Kerr, da Universidade Federal de Uberlândia, Minas Gerais, pelo fato de tratar-se de uma espécie endêmica da Mata Atlântica, agora restrita a pequena área de remanescentes em Domingos Martins e Pedra Azul, Espírito Santo.

Quando examinamos, pela primeira vez, exemplares desta espécie, pensamos que pudesse ter havido erro de etiquetagem, ou que ninhos da Amazônia houvessem sido transferidos para o Espírito Santo, já que se trata de uma espécie nitidamente relacionada com grupos da Região Amazônica, como M. seminigra Friese, 1903 e M. lateralis Erichson, 1848. Apenas o segundo grupo tem um representante no Nordeste, a "irussú do campo", como é conhecida na Bahia a $M$. scutellaris Latreille, 1811. Esta última é talvez a mais bela Melipona pelo colorido da pilosidade fulvo-arruivada do tórax e pelo contraste entre o preto da base dos tergos com as largas faixas brancas marginais. Novos ninhos encontrados em Domingos Martins pelos pesquisadores de Viçosa e Uberlândia, confirmaram a origem geográfica de $M$. capixaba.

1) Contribuição número 805 do Departamento de Zoologia, Universidade Federal do Paraná. Com apoio de FAPESP e CNPq.

2) Departamento de Zoologia, Universidade Federal do Paraná, Caixa Postal 19020, 81531-970 Curitiba, Paraná, Brasil. Bolsista do CNPq.

3) Departamento de Biologia Geral, Faculdade de Filosofia Ciências e Letras, Universidade de São Paulo, 14040-901 Ribeirão Preto, São Paulo, Brasil. Pesquisador do CNPq. 
A presença no Espírito Santo, de uma apifauna relacionada com grupos amazônicos, não é novidade. Ducke (1910: 40) já havia chamado a atenção para esse fenômeno. Em suas palavras: "Não poucas espécies, frequentes na Amazônia, faltam completamente no Ceará, para reaparecerem (ou serem substituídas por espécies de estreito parenteseo) nas matas do Espírito Santo e Rio de Janeiro ...". Para o gênero Melipona, entretanto, e de grupos de espécies possivelmente mais recentemente derivadas, este é o primeiro caso a ser relatado, e traz um interessante problema biogeográfico a ser esclarecido.

\section{Melipona (Michmelia) capixaba, sp.n.}

Figs 1-5

Operária. Rohusta, de tamanho relativamente grande: comprimento total aproximado $10,8 \mathrm{~mm}$, da asa anterior $8,9 \mathrm{~mm}$; largura da cabeça $4,52 \mathrm{~mm}$ e do segundo tergo $4,40 \mathrm{~mm}$.

Cor. Cabeça e tórax predominantemente castanho-escuros com desenhos amarelos foscos, na metade inferior da face; pernas pardo-escuras, brilhantes, variegadas de amarelo, principalmente na metade distal das tíbias e basitarsos do par posterior. Tégulas pardas com a metade externa amarelo-ocrácea; asas lavadas de amarelo-ocráceo, um pouco mais intenso na radial; estigma e venação méleoocráceos, C e R mais escuras. Propódeo castanho-escuro; tergos negro-brilhantes, com faixas marginais estreitas eshranquiçadas, completas do primeiro ao quinto; lado ventral dos dois primeiros tergos e os dois primeiros esternos amareloocráceo-claros. Desenhos da face amarelo-ocráceos; todo o clípeo com manchas pardas vagas (a linha média no terço superior de um amarelo mais vivo); estrias paroculares muito estreitas em cima terminando ao nível da tangente alveolar superior e muito alargadas embaixo até as fóveas tentoriais (o amarelo mais claro nos cantos inferiores do clípeo, extremidade inferior das estrias paroculares e nas mandíbulas, estas marginadas de castanho-pardo, com o terço distal quase preto). Labro, escapo e flagelo de um amarelo ocráceo, os flagelômeros ainda mais intensamente devido à micropilosidade.

Pontuação. Apenas com pontos pilígeros, os intervalos mates microreticulados, passando a micro-pontilhados no clípeo $(50 \mathrm{x})$ e com pontos rasos maiores na implantação das curtas cerdas; na fronte o reticulado denso, mate; no mesoscuto os pontos pilígeros mais evidentes; os intervalos aproximadamente dois diâmetros de ponto ou pouco mais, geralmente micro-mate-reticulados, porém no terço discal posterior do mesoscuto e no escutelo, principalmente neste último, os intervalos bem maiores e liso-brilhantes. Nos mesepisternos como no disco do mesoscuto, os metepisternos lisos, praticamente sem pontos. Propódeo com a área basal fortemente micro-reticulada, brilhante; os flancos mates pelo reticulado mais fino e suave. Tergos notavelmente lisos, lustrosos; com pontuação muito esparsa no disco e mais adensada aos lados, em parte com finíssimo canaliculado transversal; os dois últimos tergos praticamente iguais aos anteriores, sem canaliculado e os intervalos no disco de 4-8 diâmetros de ponto.

Pilosidade. Bastante desenvolvida na fronte, vértice e genas; com pêlos 


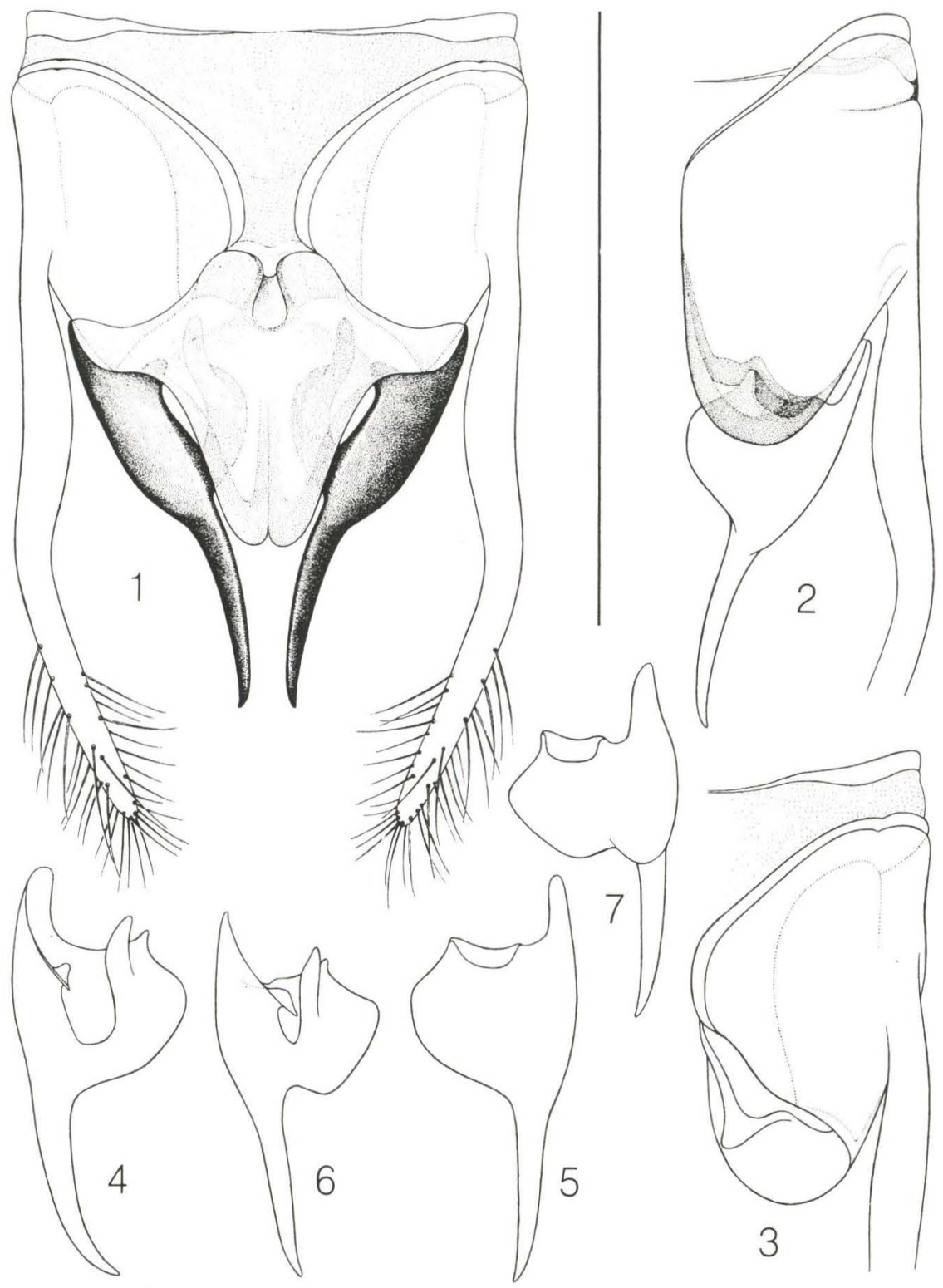

Figs 1-7. Melipona capixaba, sp.n. parátipo macho. (1) Cápsula genital, vista dorsal; (2-3) gonocoxito, vista dorsal e ventral: (4-5) valva, vista dorsal e ventral; (6-7) Melipona seminigra, macho, de Maraã, rio Japurá, Amazonas, Brasil, valva, vista dorsal e ventral. Escala $=1,0 \mathrm{~mm}$. 
finos decumbentes no clípeo, um pouco mais desenvolvidos nas paraoculares inferiores; na supraclipeal as cerdas curtas pretas eretas; na fronte e vértice bastante desenvolvida, com predominância de pêlos fulvo-pálidos nas paroculares e numerosas cerdas pretas no meio da fronte e principalmente no vértice (até 1000 micra); nas genas fulva bem mais curta, e com densa pilosidade baixa decumbente, cobrindo em grande parte o tegumento; no labro e mandíbulas pálida; no escapo fina, as cerdinhas mais longas chegando a cerca de 150 micra. No mesoscuto e escutelo longa, predominantemente preta, rodeada inferiormente no escutelo por pêlos fulvo-pálidos com cerca de 1000 micra; nos mesepisternos fulva, um pouco mais fortemente ocrácea no disco e com um tufo bastante denso de pêlos pretos por baixo da base das asas; nas pernas fulva, com algumas cerdas pretas na face externa das tíbias médias e as cerdas marginais nas posteriores, estas últimas com a metade distal fulva; nos basitarsos muito mais curtas e esparsas, as da face interna fulvas, mais regulares; na face externa curtas e mais esparsas no disco, mais grossas e bicolores no canto posterior. No propódeo pálida, mais plumosa, sem pêlos pretos. Nos tergos apenas com cerdas pretas curtas, ralas e eretas no disco, mesmo nos dois primeiros tergos; mais adensadas e mais grossas para os lados, principalmente nos tergos quarto e quinto; as mais longas neste último entre 600 e 700 micra; ventralmente pálida, no sexto esterno preta.

Forma e proporções. (As medidas entre parênteses, dadas em centésimos de milímetro). Cabeça mais larga que longa: os olhos cerca de 1,6 vezes sua largura, genas estreitas (272: 108: 72); área malar bem desenvolvida, um pouco mais longa que o diâmetro do flagelo (26: 22); órbitas claramente convergentes para baixo, fracamente sinuadas no terço superior; a interorbital superior maior que o comprimento do olho (280: 304: 268); clípeo fracamente abaulado, quase 1,5 vezes mais largo do que longo, seu comprimento cerca de $4 / 5$ da distância ao ocelo médio; os cantos inferiores muito distantes das órbitas (40), tanto quanto o diâmetro do alvéolo antenal; distância interalveolar pouco maior que o diâmetro do alvéolo, a alveolorbital duas vezes esse diâmetro (48: 80: d40); carena frontal obsoleta; distância ocelorbital cerca de dois diâmetros do ocelo, a interocelar um pouco menor (78: 66: d37); vértice estreito atrás dos ocelos (um diâmetro). Labro fortemente transversal, sem depressões; chanfro médio das mandibulas pequeno, formando dentículo mais próximo ao canto interno, separado por suave emarginação. Escapo claramente mais longo que a alveolocelar lateral, mais de 11 vezes seu diâmetro cerca de 4/9 do comprimento do flagelo e pedicelo juntos (160/14: 145: 356); flagelo longo (um pouco mais de duas vezes o escapo), com os flagelômeros mais longos que sua largura, os três primeiros como 30: 34: 34 e o diâmetro 22. Escutelo parabolóide-subtriangular, bastante convexo, fortemente declive para a base, seu comprimento $3 / 5$ da sua largura. Tíbia posterior pouco mais longa que duas vezes sua largura distal, o bordo apical levemente sinuado, o canto posterior fracamente dentiforme, o dente curtamente obtuso; basitarso mais estreito que a tíbia, 1,2 vezes mais longo que largo (180: 150), o bordo posterior em linha convexa contínua mais atenuado para a base, truncado obliquamente no ápice, o canto posterior glabro na face interna, subagudo; basitarso do segundo par de lados subpara-lelos, três vezes mais longo que largo (180: 60). Vibrissas 
fracas do segundo ao quinto, ralas e interrompidas no meio, os pêlos pouco mais longos que a largura da película translúcida marginal; esta bem desenvolvida do primeiro ao quinto tergo, finamente transverso-canaliculada, sua largura equivalente ao diâmetro do flagelo.

Macho (Figs 1-5). Extremamente semelhante às operárias, um pouco mais esbelto: comprimento total aproximado $11,6 \mathrm{~mm}$; da asa anterior $9,5 \mathrm{~mm}$; largura da cabeça $4,32 \mathrm{~mm}$, do segundo tergo $4,32 \mathrm{~mm}$.

Cor. A mesma que na operária, e com os mesmos desenhos, porém no clípeo uma grande mancha discal castanho-parda cortada pela linha média mais amarela, esbatida para baixo e ligada em cima ao contorno amarelo formando o desenho de uma âncora invertida; cantos inferiores do clípeo também amarelos; paroculares, labro, mandíbulas e antenas coloridas como nas operárias. Tergos preto-lustrosos com faixas amarelas estreitas, completas nos três primeiros, um pouco interrompidas no meio no quarto e desaparecendo no quinto.

Pilosidade. Muito semelhante à das operárias, porém com menos pêlos pretos misturados, quase nulo o tufo de pêlos pretos nos mesepisternos por baixo das asas. Cerdas no vértice e no escutelo, até 1000 micra; nos tergos curtas, eretas e esparsas, mesmo nos dois primeiros; mais adensadas para os lados; nos dois últimos tergos mais desenvolvidas, no quinto até 1000 micra e com a metade ou terço distal esbranquiçado. Cerdas nas tíbias posteriores bastante mais desenvolvidas e mais numerosas particularmente no terço distal posterior, algumas fulvo-pálidas, outras apenas na metade distal; as do bordo anterior todas fulvopálidas. As poucas cerdinhas do escapo mais curtas que seu diâmetro.

Forma e proporções. A cabeça mais larga que longa; os olhos 2,4 vezes sua largura, mais largos que as genas de perfil (272: 112: 68); a área malar quase tão longa como o diâmetro do flagelo (22: 25); órbitas convergentes para baixo, fracamente sinuosas, com a interorbital máxima maior que o comprimento do olho, a superior um pouco menor (268: 280: 232); o clípeo um pouco mais abaulado que na operária, 1,34 vezes mais largo que longo e quase tão longo como a distância clípeocelar (160: 215: 165), micro-mate reticulado, o micro-pontilhado mais evidente que na operária; distância interalveolar maior que o diâmetro do alvéolo e quase $7 / 9$ da alveolorbital (50: 65: d44), a carena frontal bem evidente na metade inferior da fronte; a distância interocelar pouco menor que a ocelorbital, 1,65 vezes o diâmetro do ocelo (66: 70: d40); o vértice estreito, sua largura atrás dos ocelos apenas um diâmetro. Labro transversal, fracamente elevado aos lados; as mandíbulas bastante sinuadas no terço interno do bordo apical, sem formar dente. Escapo mais curto que na operária, 4,67 vezes mais longo que seu diâmetro, pouco mais longo que a distância alveolocelar lateral (140: 130; d30); flagelo muito longo e juntamente com o pedicelo mais longo que três vezes o escapo (426: 140); os flagelômeros bem mais longos que sua largura, o primeiro o mais curto (37: 44: 43: d25). Escutelo fortemente triangular parabolóide, mais longo que a metade da sua largura (132: 208), bastante inchado, fortemente declive para a sutura escuto-escutelar. Mesoscuto no disco e principalmente o escutelo, ainda mais lisos que na operária. Área basal do propódeo fortemente micro-reticulada; tergos na margem com película larga, bem desenvolvida; vibrissas obsoletas; os pontos de 
implantação das cerdas bastante marcados. Basitarsos médios fracamente atenuados para o ápice, 2,83 mais longos que largos; tibia posterior duas vezes sua largura apical (290: 140), com a depressão corbicular semelhante à da operária, porém menor, o bordo distal não sinuado e o canto posterior pouco anguloso; o basitarso 1,6 mais longo que largo (170: 106), o bordo posterior menos convexo que na operária e o canto distal menos pronunciado.

Rainha virgem. Comprimento total aproximado $11,83 \mathrm{~mm}$, asa anterior $8,26 \mathrm{~mm}$; largura da cabeça $3,60 \mathrm{~mm}$, do segundo tergo $4,20 \mathrm{~mm}$.

Cor. Cabeça e tórax de um castanho quase preto, moderadamente brilhante; tergos de um preto lustroso. Desenhos amarelos: um $\mathrm{T}$ invertido no clípeo; a barra média desaparecendo no terço superior, a inferior alargada para os lados sem chegar aos cantos inferiores; a extremidade inferior das áreas paroculares, o labro, as mandíbulas de um pardo-ocráceo-claro e o bordo apical estreitamente preto. Escapo, pedicelo e flagelo pardo-ocráceos,claros. Axilas parcialmente manchadas de amarelo. Terceiro tergo na extremidade basal do postergito e todo pretergito com uma faixa amarela. Tégulas pardas, o disco e bordo externo posterior ocráceos; asas lavadas de ocráceo, um pouco mais intensamente na $\mathrm{C} \mathrm{e}$ $\mathrm{R}$; estigma e veias pardo-ocráceos, bordos mais escurecidos.

Pilosidade. Esbranquiçada na cabeça e tórax, com cerdas pretas misturadas na fronte, vértice, dorso e lados do tórax; nestes sem formar tufo subalar, mais evidentes na parte superior e anterior dos mesepisternos. Nos tergos predominantemente preta, em certa luz acastanhada, mais pardacenta para os lados; nos esternos pardo-ocrácea. Decumbente, plumosa, pardo-ocrácea mais densa na fronte, genas e lobos pronotais, muito curta no clípeo com pequenas cerdas ralas decumbentes. Cerdas no labro até 500 micra, nas mandíbulas até 500 micra, no escapo 150 micra; no vértice até 600 micra, no escutelo 1200 micra.

Pontuação. Apenas pilígera. No clípeo muito fina, os pontos das cerdinhas um pouco maiores, superficiais; nas paroculares inferiores mais esparsa embaixo. No disco do mesoscuto os intervalos lisos, polidos; no escutelo mais densa no disco. Nos tergos mais esparsa, os pontos maiores, os intervalos lisos, com micro estrias transversais interrompidas, pouco perceptíveis (50x), mais evidentes nos dois primeiros.

Forma e proporções. Cabeça um pouco mais longa que larga; os olhos 2,85 mais longos que largos, mais estreitos que as genas (200: 70: 80); interorbitais maiores que o comprimento do olho, pouco convergentes para baixo (250: 270: 240); área malar longa, duas vezes o diâmetro do flagelo (40). Clípeo uniformemente abaulado, 1,5 vezes mais largo que longo, um pouco mais curto (7/9) que sua distância ao ocelo (125: 190: 160); distância interalveolar pouco mais longa que o diâmetro do alvéolo, a alveolorbital 2 vezes (45: 70: d35); carena frontal evidente no terço inferior seguida até o ocelo por leve depressão sem formar sulco; distância interocelar $4 / 5$ da ocelorbital, esta dois diâmetros de ocelo (60: 75: d30). Labro simplesmente abaulado, transversal, quase três vezes seu comprimento (115: 40); mandíbulas com micro entalhe no bordo apical seguido até o canto interno por fraquíssima sinuosidade, o canto externo um pouco estreitado e 
recortado no bordo inferior. Escapo quase sete vezes o diâmetro, mais longo que a distância alveolocelar lateral (170: 130: d25), as cerdas bem mais curtas que o diâmetro do escapo; flagelo longo, flagelômeros segundo e seguintes 2 vezes seu diâmetro (26: 38: 38: d19). Escutelo fortemente abaulado subtriangular de ápice arredondado, seu comprimento cęrca 1,7 vezes sua largura na base, tíbias médias 1.8 vezes o comprimento do basitarso, este estreito pouco mais de 1/4 (270: 150: 40); as tíbias posteriores um pouco alargadas para o ápice, 3,33 vezes mais longas que largas (320: 96); o basitarso quase 4/7 da tíbia, estreito (180: 50), atenuado para o ápice.

Holótipo operária, e os seguintes parátipos: 11 machos, 3 rainhas virgens e 6 operárias, com etiqueta de "Dom[ingos]. Martins - E[pírito]S[anto] - BRASIL. 14/08/92, G.A.R. Melo [leg.]"; etiqueta adicional: "BR 262, Km 95"; outros 4 parátipos, operárias, de "Pedra Azul (pico de montanha a oeste de Domingos Martins), ES, 14.07.92. A.A. Goicochea Huertas"; depositados no Departamento de Biologia da Faculdade de Filosofia Ciências e Letras, Universidade de São Paulo, Ribeirão Preto (Coleção Camargo); outros parátipos do mesmo local depositados no Departamento de Zoologia da Universidade Federal do Paraná, Coleção Entomológica Pe. Jesus Santiago Moure (DZUP).

Discussão. Pela forma da genitália, especialmente pelas valvas curtas, $M$. capixaba nitidamente pertence ao grupo fasciata (SCHWARZ 1938, e MOURE \& KERR 1950) que inclui as seguintes espécies ou formas: fasciata Latreille, 1811 do México, belizae Schwarz, 1932 de Honduras, costaricensis Cockerell, 1919 e melanopleura Cockerell, 1919 da Costa Rica, panamica Cockerell, 1919 do Panamá, indecisa Cockerell, 1919 da Venezuela, eburnea Friese, 1900 da Bolívia, Peru e Acre (Brasil), fuscopilosa Moure \& Kerr, 1950 da Amazônia ocidental, seminigra Friese, 1903 (Figs 6, 7) e subespécies da Amazônia oriental e sul, lateralis Erichson, 1848 (incluindo a forma kangarumensis Cockerell, 1920) da Guiana, boliviana Schwarz, 1932 da Bolívia e scutellaris Latreille, 1811 do nordeste do Brasil.

Distingue-se facilmente de todas essas espécies, exceto boliviana, pelo tegumento do mesonoto muito liso e brilhante. De boliviana separa-se pelo tamanho maior (largura da cabeça cerca de $4,4 \mathrm{~mm}$, em boliviana, $4,0 \mathrm{~mm}$ ), pelos desenhos amarelos no clípeo e paroculares inferiores (em boliviana não há desenhos amarelos, apenas uma fraca estria ao longo da linha média do clípeo) e tórax um pouco menos liso. De scutellaris, a espécie mais próxima geograficamente, separa-se não só pelo tegumento do mesonoto liso e brilhante (em scutellaris mate, micro-ruguloso), mas também pela pilosidade fusca do mesonoto e pelas faixas pré-marginais dos tergos metassomáticos quase nulas; em scutellaris, a pilosidade do mesonoto fulvo-arruivada, as faixas pré-marginais dos tergos largas, brancas, contrastantes. Entretanto, a presença de desenhos amarelos no clípeo e paroculares inferiores em $M$. scutellaris e capixaba, sugere uma relação de espécies irmãs; pela estrutura da genitália, também são praticamente idênticas.

Etimologia. Do Tupi kapi'xawa=terra de plantação. Usado como apelido dos naturais ou habitantes do Espírito Santo. 


\section{REFERÊNCIAS BIBLIOGRÁFICAS}

Ducke, A. 1910. Explorações Botânicas e Entomológicas no Estado do Ceará. Rev. Trimes. Inst. Ceará 24: 3-61.

Moure, J.S. \& W.E. Kerr. 1950. Sugestões para a Modificação da Sistemática do Gênero Melipona (Hymen. Apoidea). Dusenia 1 (2): 105-129.

Schwarz, H.H. 1932: The genus Melipona: The Type Genus of the Meliponidae or Stingless Bees. Bull. Amer. Mus. Nat. Hist. 63: 231-460.

Recebido em 01.III.1994; aceito em 13.V.1994. 